\title{
Selective apoptosis induction in MCF-7 cell line by truncated minimal functional region of Apoptin
}

Lim Shen $\mathrm{Ni}^{1}$, Zeenathul Nazariah bt Allaudin ${ }^{1,2^{*}}$, Mohd Azmi b Mohd Lila², Abas Mazni b Othman ${ }^{3}$ and Fauziah bt Othman ${ }^{4}$

\begin{abstract}
Background: Chicken Anemia Virus (CAV) VP3 protein (also known as Apoptin), a basic and proline-rich protein has a unique capability in inducing apoptosis in cancer cells but not in normal cells. Five truncated Apoptin proteins were analyzed to determine their selective ability to migrate into the nucleus of human breast adenocarcinoma MCF-7 cells for inducing apoptosis.

Methods: For identification of the minimal selective domain for apoptosis, the wild-type Apoptin gene had been reconstructed by PCR to generate segmental deletions at the $\mathrm{N}^{\prime}$ terminal and linked with nuclear localization sites (NLS1 and NLS2). All the constructs were fused with maltose-binding protein gene and individually expressed by in vitro Rapid Translation System. Standardized dose of proteins were delivered into human breast adenocarcinoma MCF-7 cells and control human liver Chang cells by cytoplasmic microinjection, and subsequently observed for selective apoptosis effect.

Results: Three of the truncated Apoptin proteins with N-terminal deletions spanning amino acid 32-83 retained the cancer selective nature of wild-type Apoptin. The proteins were successfully translocated to the nucleus of MCF-7 cells initiating apoptosis, whereas non-toxic cytoplasmic retention was observed in normal Chang cells. Whilst these truncated proteins retained the tumour-specific death effector ability, the specificity for MCF-7 cells was lost in two other truncated proteins that harbor deletions at amino acid 1-31. The detection of apoptosing normal Chang cells and MCF-7 cells upon cytoplasmic microinjection of these proteins implicated a loss in Apoptin's signature targeting activity.

Conclusions: Therefore, the critical stretch spanning amino acid 1-31 at the upstream of a known hydrophobic leucine-rich stretch (LRS) was strongly suggested as one of the prerequisite region in Apoptin for cancer targeting. Identification of this selective domain provides a platform for developing small targets to facilitating carriermediated-transport across cellular membrane, simultaneously promoting protein delivery for selective and effective breast cancer therapy.
\end{abstract}

Keywords: VP3, Apoptin, MCF7 cells, Chang cells, Apoptosis, Microinjection, Truncation

\footnotetext{
* Correspondence: zeenathul@upm.edu.my

'Institute of Biosciences, Universiti Putra, Serdang, Malaysia

${ }^{2}$ Faculty of Veterinary Medicine, Universiti Putra Malaysia, Serdang, Selangor 43400 UPM, Malaysia

Full list of author information is available at the end of the article
} 


\section{Background}

In the new era of biotechnology, the study in mass production of recombinant protein has attracted a lot of attention towards protein therapy which can readily overcome the limitations faced in gene therapy and plasmid DNA-based vaccines. The genetic elements of plasmid as a propagation and expression units as well as their host genome for the production of recombinant plasmid DNA are still a safety concern for clinical use $[1,2]$. On the other hand, protein therapy can overcome this problem by being highly specific in action with less potential to interfere with normal biological process and without the need to be activated for gene expression [3].

Apoptin is a small protein of 121 amino acids (a.a.) derived from chicken anemia virus (CAV) (Noteborn et al., [4]) and possess tumor-specific apoptosis-inducing activity. In tumor cells, it predominantly co-localizes with heterochromatin and nucleoli, followed by induction of apoptosis in various cultured human tumorigenic and/or transformed cell lines such as breast and lung tumor, leukemia, lymphoma, osteosarcoma melanoma, cholangiocarcinoma, hepatoma and bladder cancer cells $[5,6]$.

Apoptin is predominantly found in the nucleus of transformed and tumor cells, whereas in untransformed cells, it localizes the cytoplasm. The a.a. sequence of Apoptin contains two basic stretches constituting putative nuclear localization signals (NLS) and a stretch of nuclear export signal (NES) [7]. The nuclear localization regions contain a bipartite-type NLS (a.a. 82-88 and 111-121) and the distinct parts of Apoptin have independent, intrinsic cell killing activity strongly correlated with induction of cell death (Danen-van et al., [8]). Whilst, NES residues at a.a. 97-105 enable the Apoptin transportation from the nucleus to cell cytoplasm [7]. Apoptin also comprises of a hydrophobic leucine-rich stretch (LRS) at a.a. 33-46 which assists in Apoptin nuclear accumulation that act as nuclear retention sequence [9].

Although popularly investigated, the mechanism of Apoptin's tumor-specific apoptosis activity remains to be fully elucidated. The protein becomes specifically phosphorylated and activated by a kinase activity found only in tumor or transformed cells. Apart from nuclear targeting signals, phosphorylation site at threonine-108 (Thr-108) is pivotal in transducing apoptotic signals in cancerous cells [10]. However, some findings reported the partial influence of $\mathrm{Thr}-108$ phosphorylation in apoptotic activity $[11,12]$. Recent finding by Lanz indicated the role of proteasome in Apoptin degradation but had no influence on the amount of Apoptin in tumor cells, although it affects p53 level. Normal cells stabilize the Apoptin and p53 levels [13]. On other hand, Yuan L. et al. demonstrated Apoptin bound to heat shock protein 70 (HSP70), an anti-apoptotic protein, causing downregulation of HSP70 expression and subsequent apoptosis induction in tumor cells. Apoptin has no effect on HSP70 that was not activated in normal cells. Thus, this study explained why apoptotic effect occursin tumor cells only and not in normal cells [14].

The main aims of this study are i) to determine the minimal functional site of Apoptin, ii) to assess the contribution of LRS in the absence of NES, iii) to analyze the early cytoplasmic events in the subcellular trafficking of truncated Apoptins and iv) to explore the feasibility of direct delivery of truncated Apoptins as antitumor agents. The recombinant truncated Apoptin proteins that were fused with maltose-binding protein (MBP) at their $\mathrm{N}$-terminus were produced by in vitro protein expression system. Maltose binding protein (MBP) fused Apoptin exists as a stable, homogenous globular multimeric complex, which presents the active form of Apoptin in vivo [15]. MBP causes neither toxicity nor apoptosis of cells. Prokaryotically expressed recombinant MBP-Apoptin protein maintains its tumor-specific killing and localization properties, indicating that a mammalian-specific folding environment is not a necessity [16]. In this study, we hypothesize that the presence of minimal selective domain in truncated Apoptin complexes directs the apoptotic induction in cancerous cells.

\section{Methods}

\section{Construction of truncated MBP-apoptin plasmids}

Plasmids-pIVEX-MBP (Roche Diagnostic, Germany) was used for the expression of proteins as fusions to the C-terminus of MBP (maltose binding protein). PCR was conducted to amplify 5 sets of DNA fragment Apoptin (Patent: PI20100031130); VP3A1-69N1N2, VP3A1-46N1N2, VP3A1-31N1N2, VP3A32-69N1N2 and VP3A32-62N1N2. Nine sets of primers were used to amplify the DNA fragments according to the designated truncation (Figure 1). The DNA fragments were then digested with Nco1 and Xho1 and ligated into pIVEX-MBP vectors at the $\mathrm{C}$ terminus of MBP with the appropriate linkers in between Nco1 and Xho1, generating pMBP-VP3 (a.a 1121), pMBP-VP3A1-69N1N2 (a.a 1-69 with NLS1 and NLS2), pMBP-VP3A1-46N1N2 (a.a 1-46 with NLS1 and NLS2), pMBP-VP3A1-31N1N2 (a.a. 1-31 with NLS1 and NLS2), pMBP-VP3A32-69N1N2 (a.a. 32-69 with NLS1 and NLS2) and pMBP-VP3A32-62N1N2 (a.a. 32-62 with NLS1 and NLS2) (Figure 1).

\section{Protein expression}

Proteins of the constructs pMBP-VP3, pMBP-VP3A169N1N2, pMBP-VP3A1-46N1N2, pMBP-VP3A1-31N1N2, pMBP-VP3A32-69N1N2 and pMBP-VP3A32-62N1N2 were expressed by using in vitro protein synthesis system, Rapid Translation System (RTS) (5 Prime, Germany) according to manufacturer's instruction. Briefly, RTS uses a 


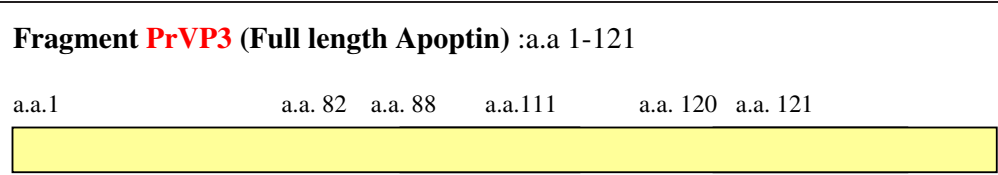

Fragment A (named PrVP3A1-69N1N2):

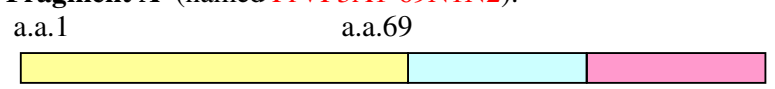

Fragment B (named PrVP3A1-46N1N2):

a.a.1 a.a.46

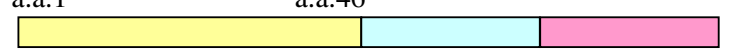

Fragment C (named PrVP3A1-31N1N2):

a.a.1 a.a.31

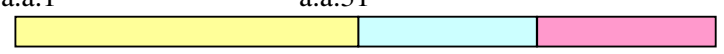

Fragment D (named PrVP3A32-69N1N2):

a.a.32 a.a.69

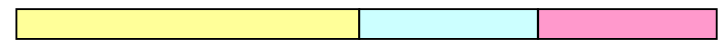

Fragment E (named PrVP3A32-62N1N2):

a.a.32 a.a.61

Figure 1 Diagrammatic design of Apoptin (PrVP3) and truncated Apoptins. (PrVP3A1-69N1N2, PrVP3A1-46N1N2, PrVP3A1-31N1N2, PrVP3A32-69N1N2, PrVP3A32-62N1N2).

cell-free protein production system by utilizing an enhanced E. coli lysate to perform coupled in vitro transcription-translation reactions.

\section{Western blot assay}

The expressed fusion proteins were separated by SDS PAGE and confirmed via Western blot assay by using antiVP3 monoclonal antibody (mAb) (TropBio, Australia) and anti-MBP mAb (New England Biolabs, USA).

\section{Protein purification}

The expressed proteins were purified by amylose resin (New England Biolabs, USA). $300 \mu \mathrm{l}$ of amylose resin was added into purification column. The column was equilibrated with 8 column volumes equilibration buffer (10 mM Tris- $\mathrm{HCl}, \mathrm{pH}$ 7.2). The expressed protein was applied into the column by gravity flow. The column flow was shut off after the entire sample has entered the column. The column was incubated for $30 \mathrm{~min}$. The column was washed with 10 bed volumes of wash buffer (10 mM Tris- $\mathrm{HCl}, 1 \mathrm{M} \mathrm{NaCl}, \mathrm{pH}$ 7.2). The protein was eluted with 4 bed volumes of elution buffer $(10 \mathrm{mM}$ Tris- $\mathrm{HCl}, 20 \mathrm{mM}$ maltose, $\mathrm{pH}$ 7.2). The eluted protein was concentrated using Vivaspin 2 Concentrator (Vivascience, Germany).

\section{Cells}

Experiments were performed onMCF-7 (provided by Professor Fauziah Othman, Faculty of Medicine, University Putra Malaysia) and non-cancerous human liver cell (Chang's cell) (provided by Associate Professor DrZeenathul Nazariah Allaudin, Faculty of Veterinary, University Putra Malaysia. The maintenance medium for both cell lines contained RPMI supplemented with 10\% fetal bovine serum (FBS) and an antibiotic solution (100 units/ml penicillin, $100 \mu \mathrm{g} / \mathrm{ml}$ streptomycin). All cell culture media and supplements were from Gibco Invitrogen Life Sciences (Paisley, UK). Both MCF-7 cells and Chang cells were plated at a density of $2 \times 10^{3}$ onto a cover slip with size $22 \times 22 \mathrm{~mm}^{2} 24 \mathrm{~h}$ prior to microinjection.

\section{Microinjection}

Apoptin protein was delivered into MCF-7 cells and Chang cells through microinjection. Optimization of cellular microinjection has been previously established in our laboratory by using MBP protein (Lim et al., [17]). $6 \mu \mathrm{g}$ of protein was loaded into Femtotips I (Eppendorf, USA) by microloader and injected into the targeted cells under an injection pressure ranging from $30-110 \mathrm{hPa}$ for 0.5 s. A total number of 50 cells per cover slip were injected. 
After microinjection, the injected cells were immersed in rich RPMI 1640 media which contained 10\% FBS serum and incubated at $37^{\circ} \mathrm{C}$ in $5 \% \mathrm{CO}_{2}$ incubator. The injected cells were incubated at various time points; $2 \mathrm{hr}$ and $10 \mathrm{hr}$ prior to immunofluorescence assay and $5 \mathrm{hr}$ and $15 \mathrm{hr}$ before the apoptosis assay.

\section{Immunofluorescence}

The microinjected cells were fixed after incubation of injected cells at various time points at $2 \mathrm{hr}$ and $10 \mathrm{hr}$. At different time points, the cells were fixed by immersing the cover slip in $100 \%$ ice-colded methanol for $20 \mathrm{~min}$ at $0^{\circ} \mathrm{C}$ and washed thrice with PBS for $5 \mathrm{~min}$ each. The cover slip was then immersed in $2 \mathrm{ml}$ antiMBP mouse monoclonal antibody (Chemicon, USA) at dilution $1: 1000$ in $10 \mathrm{mM}$ PBST buffer $(3.2 \mathrm{mM}$ $\mathrm{Na}_{2} \mathrm{HPO}_{4}, 0.5 \mathrm{mM} \mathrm{KH} \mathrm{PO}_{4}, 1.3 \mathrm{mMKCl}, 135 \mathrm{mM}$ $\mathrm{NaCl}, 0.05 \%$ Tween 20, pH 7.4) at RT for an hour. The cover slip was given again PBST buffer wash for 3 times at $5 \mathrm{~min}$ each. Two $\mathrm{ml}$ of goat anti-mouse IgG fluorescein conjugated secondary antibody at dilution of 1:200 in $1 \mathrm{M}$ PBST was used for $1 \mathrm{hr}$ at RT. Subsequently, 3 PBST washes were done for $5 \mathrm{~min}$ each. The FITC stained cells were mounted with anti-fade agent and analyzed under fluorescence microscopy (Zeiss, USA) and the images were captured by digital image analysis equipment.

\section{Apoptosis assay}

Injected cells were incubated with Annexin $\mathrm{V}$ reagent, ApopNexin FITC Apoptosis Detection kit (Chemicon, USA) to detect the appearance of the apoptotic cells. At various time points of incubation, the supernatant in the $35 \mathrm{~mm}$ petri dish that contained detached cells was collected into a microtube and spun down at $400 \times \mathrm{g}$ for 5 min at $4^{\circ} \mathrm{C}$. The supernatant was discarded and the pelleted cells were collected. The collected cells were resuspended with $200 \mu \mathrm{l} 1 \mathrm{X}$ binding buffer and spun again at $400 \times$ g for $5 \mathrm{~min}$ at $4^{\circ} \mathrm{C}$ to collect the cells. This step was repeated twice to wash the detached cells. Meanwhile, those cells attached at the cover slip were washed twice with $200 \mu \mathrm{l} 1 \mathrm{X}$ binding buffer. After the washing step, $200 \mu \mathrm{l}$ of $1 \mathrm{X}$ binding buffer and $3 \mu \mathrm{l}$ of ApopNexin FITC were added into the collected cells and mixed well. The mixture was then transferred onto the washed coverslip and incubated for $15 \mathrm{~min}$ at RT. After $15 \mathrm{~min}$ of incubation, $2 \mu \mathrm{l}$ of counterstain, PI (Chemicon, USA) was added onto the coverslip equally and incubated again for $15 \mathrm{~min}$ on ice. Finally, the coverslip that contained attached and detached (flowing) cells were mounted with anti-fade agent, viewed under fluorescence microscope (Zeiss, USA) and the image captures were done by digital image analyzer.

\section{Results}

\section{Construction of truncated apoptin gene}

Five truncated Apoptin fragments were amplified and constructed in pIVEX-MBP vector. The plasmids expressing $\mathrm{MBP}$ and fusions of $\mathrm{MBP}$ and parts of Apoptin protein have been generated. All the recombinant proteins have $\mathrm{MBP}$ at the $\mathrm{N}$ terminus of Apoptin protein. The constructed genes were named i) pMBP-VP3A169N1N2 (a.a 1-69 with NLS1 and NLS2), ii) pMBPVP3A1-46N1N2 (a.a 1-46 with NLS1 and NLS2), iii) pMBP-VP3A1-31N1N2 (a.a. 1-31 with NLS1 and NLS2), iv) pMBP-VP3A32-69N1N2 (a.a. 32-69 with NLS1 and NLS2), v) pMBP-VP3A32-62N1N2 (a.a. 3262 with NLS1 and NLS2) with lengths $261 \mathrm{bp}, 191 \mathrm{bp}$, $150 \mathrm{bp}, 174 \mathrm{bp}$ and $150 \mathrm{bp}$ respectively (Figure 2).

\section{Determine translocation of truncated VP3 protein}

Proteins of interest were successfully expressed using RTS kit (5 Prime, Germany) within $6 \mathrm{hr}$ of incubation and purified by amylose resin. Western blot assay verified the presence of protein of interest (Figure 3A). The findings showed positive expression for full-length and truncated Apoptin proteins. Apoptin, MBP protein (PrMBP) and its truncated proteins (PrVP3A1-69N1N2, PrVP3A1-46N1N2 and PrVP3A1-31N1N2 were analyzed by anti-VP3 mAb. All except for PrVP3A32-69N1N2 and PrVP3A32-62N1N2 proteins could be detected using this mAb (Figure 3). PrVP3A32-69N1N2 and PrVP3A32-62N1N2 can only be detected using anti-

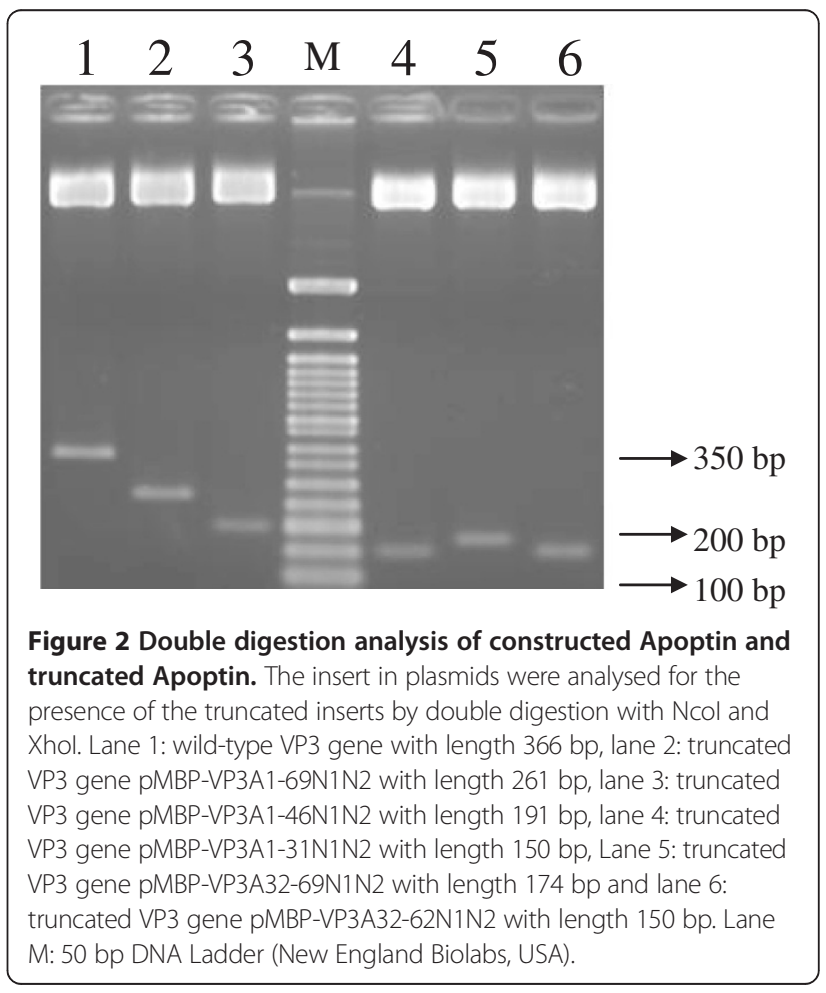




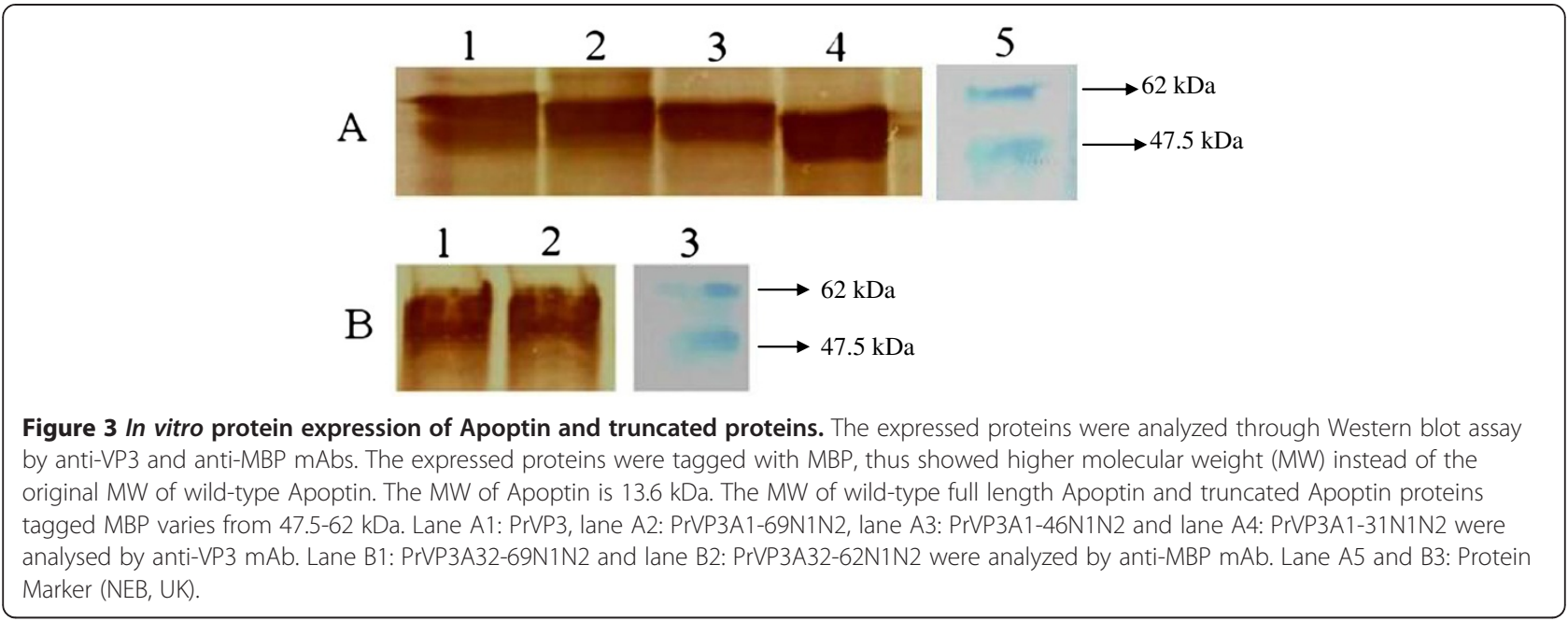

MBP mAb (Figure 3). The desired proteins from truncated constructs were expressed efficiently as well as rapidly by using in vitro protein expression system.

\section{Detection of apoptin and truncated apoptin proteins in injected normal and cancerous cells}

Seven purified recombinant proteins including wild-type Apoptin (PrVP3), and truncated Apoptin proteins, PrVP3A169N1N2, PrVP3A1-46N1N2, PrVP3A1-31N1N2, PrVP3A3269N1N2, PrVP3A32-62N1N2 and negative control, PrMBP were successfully delivered into MCF7 and Chang cell respectively. The cells that were successfully microinjected with proteins were shown in Figure 4 and Figure 5 . All the proteins were successfully delivered into the cytoplasm of MCF7. Nuclear translocation was observed in cells microinjected with wild-type Apoptin (PrVP3) and truncated Apoptin proteins, PrVP3A1-69N1N2, PrVP3A1-46N1N2, PrVP3A1-31N1N2, PrVP3A32-69N1N2 and PrVP3A32-62N1N2. In non-cancerous Chang cells, Apoptin proteins (PrVP3), PrVP3A1-69 N1N2, PrVP3A1-46N1N2, PrVP3A1-31N1N2, PrVP3A3269N1N2, PrVP3A32-61N1N2 and PrMBP proteins were found retained at the cell cytoplasm. Contrarily, nuclear translocation of wild-type and truncated proteins were not observable at $10 \mathrm{hr}$ post-microinjection.

\section{Apoptotic effect of truncated VP3 protein in MCF cells and Chang cells}

Both MCF7 cells and Chang cells were harvested at various time points to detect the apoptotic cells (Figure 6 and Figure 7). Cells without injection (MCF-7 cells and Chang cells) were either viable or have undergone necrosis showing none or halogreen or both green and red fluorescence signal respectively (Figures 6 and 7). PrVP3, PrVP3A1-69N1N2, PrVP3A1-46N1N2 and PrVP3A1$31 \mathrm{~N} 1 \mathrm{~N} 2$ treatment induced apoptosis in MCF7 cells but not in Chang cells, whilst both PrVP3A32-69N1N2 and
PrVP3A32-62N1N2 caused apoptotic effect in both MCF7 cells and Chang cells (Figure 6 and Figure 7).

The recombinant proteins, PrVP3, and PrVP3A169N1N2, PrVP3A1-46N1N2,PrVP3A1-31N1N2, PrVP3A 32-69N1N2 and PrVP3A32-62N1N2 caused apoptosis in MCF7 at $15 \mathrm{hr}$ post-microinjection as shown in Figure 6. During early hour of post-microinjection ( $5 \mathrm{hr}$ ), a few apoptotic cells were detected in MCF7 cells. However, both PrVP3A32-69N1N2 and PrVP3A32-69N1N2 proteins induced apoptosis in Chang cells (Figure 7).

PrMBP served as the negative control to the recombinant Apoptin protein, where Apoptin protein and truncated Apoptin proteins were fused to the $\mathrm{N}$ terminal of the MBP protein. As expected, PrMBP did not cause any apoptosis effect in both cancerous cells and normal cells. Besides, MBP protein does not have any cytotoxic effect on cancerous cell line nor normal cell line (Figures 6 and 7).

\section{Discussion}

In this study, the wild-type and truncated Apoptins were delivered via cytoplasmic microinjection. To date; needle-microinjection is widely used for the study of many different cell responses in various fields such as cytology, physiology, genetic engineering, molecular biology, virology, tumor biology, developmental biology, pharmacology and toxicology. The injected reagents include cellular organelles, proteins, enzymes, antibodies, genes, metabolites, ions, DNA constructs, RNA, various markers and peptides [18]. This method was of preference over other delivery approach because i) protein with fixed amount could be injected into the cells, ii) an active protein could be injected into the cells instead of transferring the plasmid into the cells for gene activation and protein expression, and iii) a fixed number of cells could be injected to optimize towards a standardized approach $[18,19]$. Therefore, direct injection of protein to 


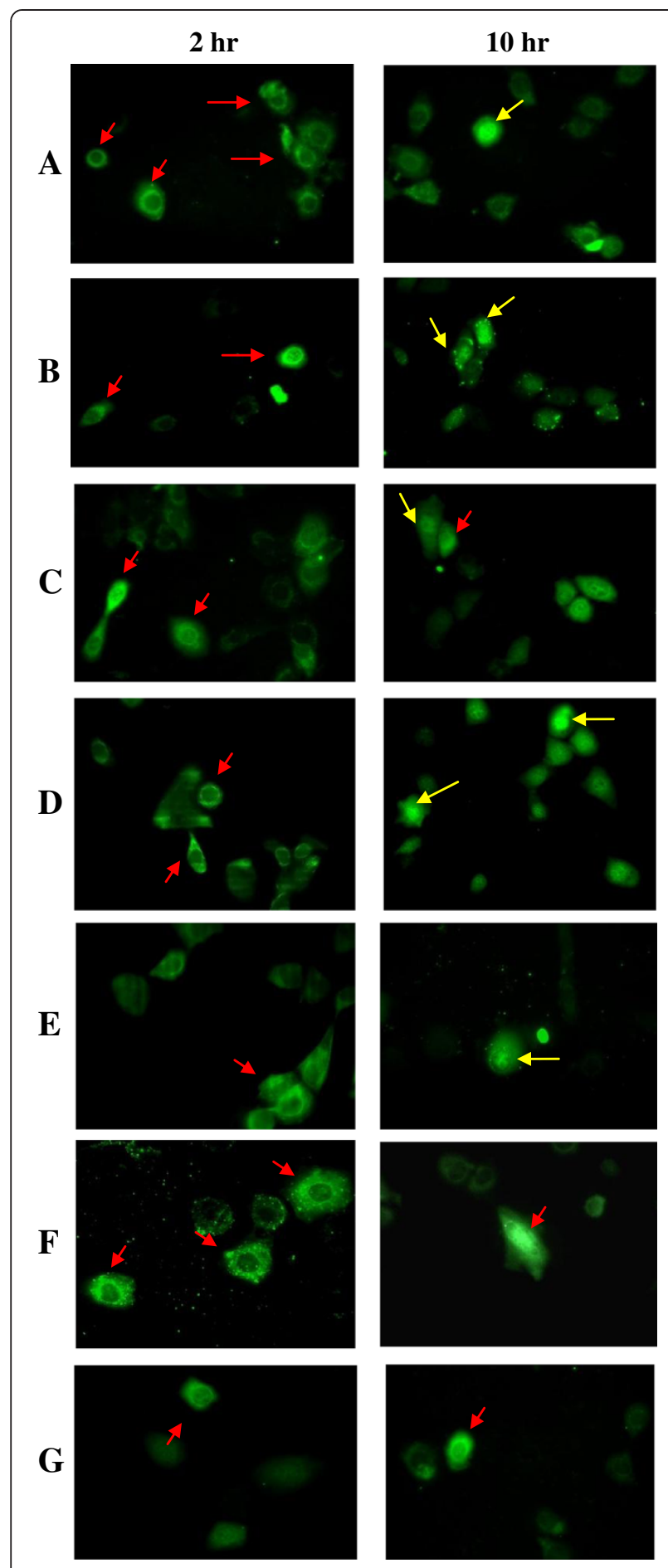

Figure 4 Indirect immunofluorescence assay on microinjected MCF7 cells with VP3 protein and truncated VP3 protein. The MCF7 cells were injected with A) PrVP3, B) PrVP3A1-69N1N2, C) PrVP3A146N1N2, D) PrVP3A1-31N1N2 E) PrVP3A32-69N1N2, F) PrVP3A32-62N1N2 and negative control, G) PrMBP. The microinjected cells were assayed at $2 \mathrm{hr}$ and $10 \mathrm{hr}$. The green fluorescence showed the present of injected protein. At $2 \mathrm{hr}$, the injected protein was detected in the cytoplasm of the cells (showed in red arrow), whereas the protein was found in the nucleus of the cells at $10 \mathrm{hr}$ (showed in yellow arrow) except PrMBP (G).

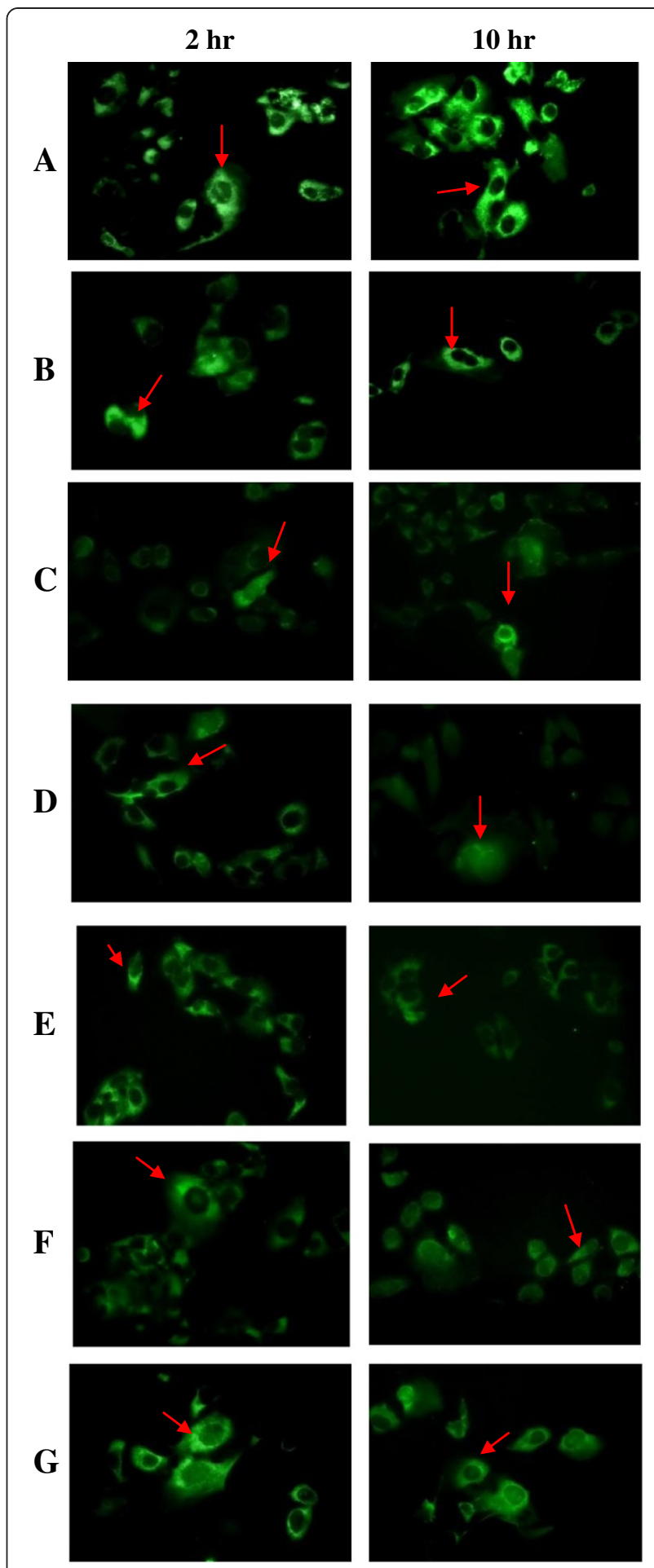

Figure 5 Indirect immunofluorescence assay on microinjected Chang cells with VP3 protein and truncated VP3 protein. Chang cells were injected with A) PrVP3, B) PrVP3A1-69N1N2, C) PrVP3A146N1N2, D) PrVP3A1-31N1N2 E) PrVP3A32-69N1N2, F) PrVP3A3262N1N2 and negative control, G) PrMBP. The microinjected cells were assayed at $2 \mathrm{hr}$ and $10 \mathrm{hr}$. At both time points, the injected protein (with green fluorescence) was detected at the cell cytoplasm (shown in red arrow). 


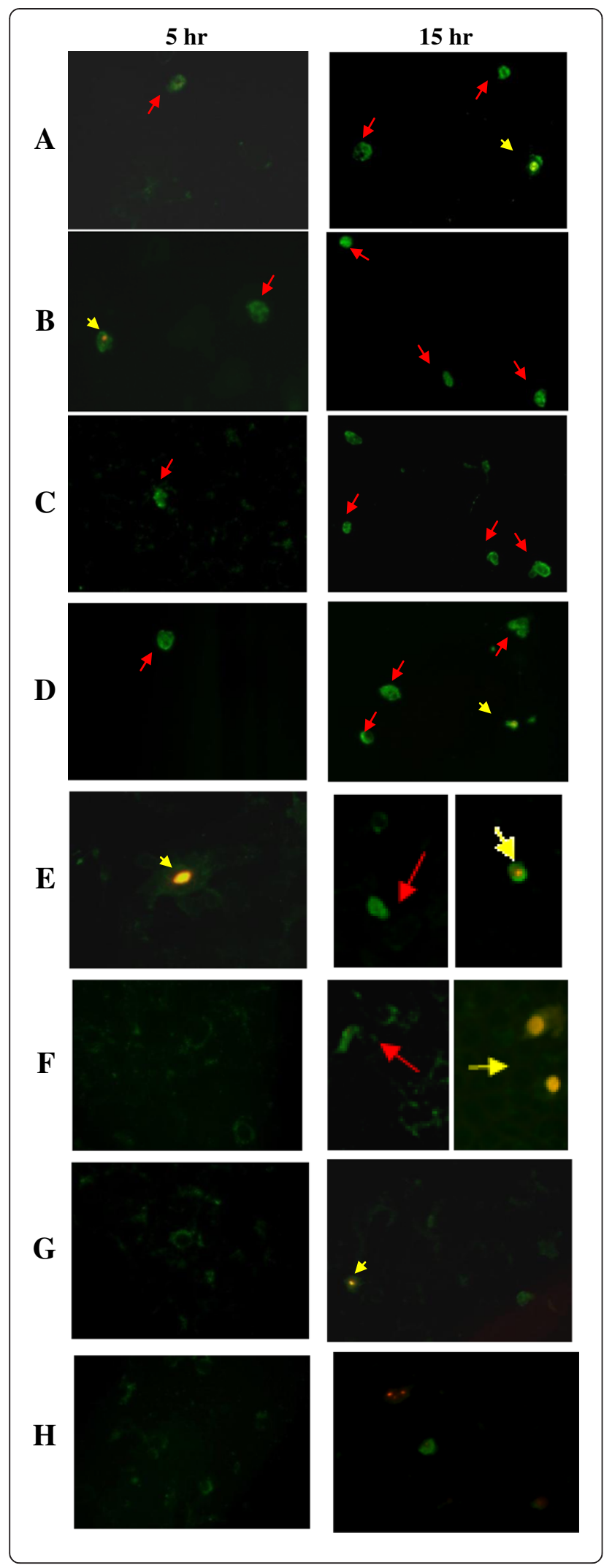

Figure 6 Detection of Apoptotic MCF7 cells by Annexin V and PI. MCF7 cells that were microinjected with A) PrVP3, B) PrVP3A169N1N2, C) PrVP3A1-46N1N2, D) PrVP3A1-31N1N2, E) PrVP3A3269N1N2, F) PrVP3A32-62N1N2, G) negative control PrMBP and H) non-injected cells were analyzed by Annexin $\mathrm{V}$ assay at $5 \mathrm{hr}$ and $15 \mathrm{hr}$. Green fluorescence signal in the cell showed the presence of apoptotic cells (red arrow), on the other hand the presence of both green and red fluorescence in the cell indicated cell necrosis (yellow arrow). Lesser apoptotic cells were observed at $5 \mathrm{hr}$ than $15 \mathrm{hr}$.

cells was an essential step in our work to predict the outcome of various truncated Apoptins, by passing the possibility of loss of expression when using recombinant plasmid or viral DNA [1,2].

This article described the generation of MBP-tagged truncated CAV-VP3 recombinant proteins and their effect in normal and cancerous cells. Apoptin protein is aggregated, shielded and degraded in the cytoplasm of normal cell [20]. In transformed cells, Apoptin is translocated into the nucleus and caused apoptosis via activation by the tumor-specific pathway [21]. Previous finding by Danen-van Oorschot and colleagues (2003) indicated reduced cell killing activity upon deletion of either N-terminal (a.a. 1-69) or C-terminal (a.a. 70-121) halves of Apoptin. Protein consisting the $\mathrm{N}$-terminal (a.a 1-69) was found in the cytoplasm whereas the Cterminal (a.a 70-121) protein resided in cell nucleus [8]. Although, the NLS signals which shuttle the expressed protein in the nucleus were intact in the C-terminal protein and as anticipated, the protein managed to be translocated into the nucleus, the apoptosis effect was still low (Danen-Van et al., [8]). Their finding was further justified by Leliveld and associates [5].

Heilman and coworkers reveal a hydrophobic leucinerich stretch (LRS) at a.a. 33-46 in N-terminal which acts as self-association region and binding region for promyelocytic leukemia protein and other protein partner [22]. This LRS has influence in nuclear accumulation, whereby deletion or mutation at this region could reduce nuclear accumulation and thus reducing the tumor cell-specificity nuclear targeting signal-dependent nuclear accumulation [10]. In addition to the NLSs which resides at a.a. $82-88$ and a.a. 111-121, the Cterminal of Apoptin has a nuclear export sequence (NES) at a.a. 97-105 [7]. NES acts as a nuclear export signal and it is important in contributing to the ability of the Apoptin to be strongly localized in tumor cells instead of normal cells [9]. The C-terminal also consists a phosphorylation site (Thr-108) that assists in driving Apoptin for nuclear accumulation via inactivation of NES in tumor cells (Rohn et al., [10]). However, Thr-108 phosphorylation has only partial effect on Apoptin's apoptotic activity and it is not required for the tumorspecific nuclear localization [11]. 


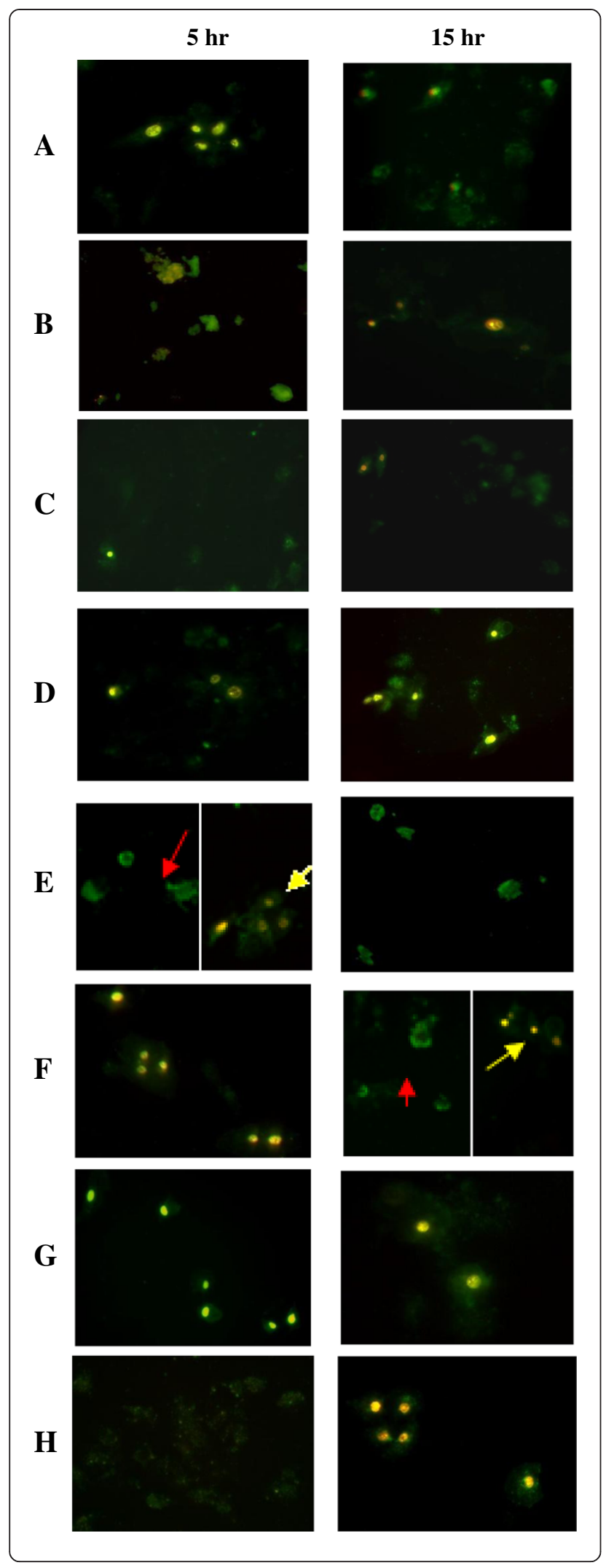

Figure 7 Apoptosis assay in non-cancerous Chang cells. Chang cells that were microinjected with A) PrVP3, B) PrVP3A1-69N1N2, C) PrVP3A1-46N1N2, D) PrVP3A1-31N1N2, E) PrVP3A32-69N1N2, F) PrVP3A32-62N1N2, G) negative control, PrMBP and H) noninjected cells were analyzed by Annexin $V$ assay at $5 \mathrm{hr}$ and $15 \mathrm{hr}$. Both green and red fluorescence signal in the cell showed the presence of necrotic cells (yellow arrow). No apoptotic cell was detected in $\mathbf{A}-\mathbf{D}$ and $\mathbf{G}$. Green fluorescence in $\mathbf{E}$ and $\mathbf{F}$ showed the presence of apoptotic cells at $15 \mathrm{hr}$ time point (red arrow).

In the present study, 5 sets of truncated proteins were derived from the wild-type Apoptin, with each consists a combination of selective regions at $\mathrm{N}$-terminal and NLSs. All the truncated Apoptin proteins contained both NLSs, and the differences between them were in the combination at $\mathrm{N}$-terminal. Apoptin region at a.a. 1-69, a.a. $1-45$, a.a. $1-31$, a.a. $32-69$ and a.a. $32-62$ were selected to combine with NLSs respectively with the presence of LRS (a.a. 33-46) and in the absence of NES (a.a. 97-105) and $\mathrm{T}^{108}$. Similar to the wild-type Apoptin, all the truncated recombinant proteins were still found at the cytoplasm (injection site) of both cell types at the beginning of injection ( $2 \mathrm{hr}$ time point). Later in the event at $10 \mathrm{hr}$ post-microinjection, the truncated ApoptinPrVP3A169N1N2, PrVP3A1-46N1N2, and PrVP3A1-31N1N2 were detected in the nucleus of MCF7 cells and cytoplasm of Chang cells. This indicated the equivalent ability of those truncated Apoptin to that of wild-type to translocate protein to the nucleus. These truncated proteins retained the ability in inducing apoptotic effect selectively to cancerous cells. Although previous work indicated a limit in apoptotic activity when using either $\mathrm{N}$-terminal or C-terminal (Danen-Van et al., [8]), combination of minimal functional sites from both terminals managed to induce apoptosis in MCF-7. Nevertheless, due to the nature of the experiment which required individual protein injection into each cell to standardize the injected protein dose, the number of cells investigated was not permissive for quantitative measurement.

Intriguingly, PrVP3A32-69N1N2 and PrVP3A32-62N1N2 induced apoptosis in both MCF7 cells and Chang cells. Both proteins had deletion at a.a. 1-31, which was an upstream of LRS region. Deletion of this region has led to an unpredictable selectivity of Apoptin. In a previous study, NES linked truncated Apoptin (a.a. 70-121) showed apoptosis in tumor cells but not in normal cells (Danen-von et al., [8]). However, the present study demonstrated that the presence of LRS in the absence of NES was sufficient to induce apoptosis in cancerous cells, provided the upstream of LRS (a.a. 1-31) was retained. Previously, a truncated Apoptin lacking LRS and its upstream region (a.a. 1-31), whilst retaining NES, NLS1, NLS2 and T108 regions managed to apoptosize cancer cells selectively (Danen-von et al., [8]). Contrarily, this study had proven that cancerous cells selectivity were not totally dependent on the presence 
of NES. A recent study by Yang and associates showed deletion of a.a 1-30 retained the characteristic nature of Apoptin in the bladder cancer cells [23]. The only significant difference between Yang's group and ours was the standardized microinjection-mediated-truncated protein delivery versus cell transfection of recombinant plasmid DNAs for expressing truncated proteins within. Another aspect of concern would be the potential induction of apoptosis in normal cells during Apoptin abundance in cytoplasm which might correlate to the nature of transduction [24]. Successfully delivery of Apoptin into cells and efficient expression of Apoptin are essential requirements. Trans-acting activator of transcription (TAT) protein transduction domain (PTD) has been demonstrated to be an ideal agent of delivering Apoptin into cells and $E$. coli plays an important role in expressing full length Apoptin [25].

Trans-acting activator of transcription (TAT) protein transduction domain (PTD) has been demonstrated to be an ideal agent of delivering Apoptin into cells and E. coli plays an important role in expressing full length Apoptin [25,26].

\section{Conclusions}

We have demonstrated selective apoptosis induction in MCF-7 cells upon standardized dose administration of PrVP3A1-69N1N2, PrVP3A1-46N1N2, and PrVP3A1$31 N 1 N 2$. All the 3 truncated proteins consist an upstream region from the known LRS, spanning at a.a. 1-31. The loss of selectivity for MCF-7 cells in both PrVP3A3269N1N2 and PrVP3A32-62N1N2 could be implicated by the absence of this critical region which strongly suggested as an indispensable domain for target the apoptosis. This study warrants further work towards quantifying the level of apoptosis induced by these truncated proteins, with a linked-within protein-transduction-domain (PTD).

\section{Abbreviations}

a.a: Amino acid; LRS: Hydrophobic leucine-rich stretch; MBP: Maltose binding protein; NLS: Nuclear localization site.

\section{Competing interests}

The authors declare that they have no competing interests.

\section{Authors' contributions}

LSN carried out the molecular genetic studies and immunoassays, participated in the sequence alignment and drafted the manuscript. ZNA participated in the design of the study, performed the statistical analysis and helped to draft as well as proofread the manuscript. MML, AMO. and FO have supported and facilitated in the research work progress. All the authors have read and approved the final manuscript.

\section{Acknowledgement}

The authors would like to thank and acknowledge Majlis Kanser Nasional (MAKNA) and Universiti Putra Malaysia for providing financial support under the research grant Apovax-MAKNA and Research University Grants (RUGS) (05-02-11-1424RU). In addition, we thank LIVES, Institute of Bioscience, Universiti Putra Malaysia and Institute of Agrobiotechnology (ABI) for providing the research environment and necessary facilities.

\section{Author details}

Institute of Biosciences, Universiti Putra, Serdang, Malaysia. ${ }^{2}$ Faculty of Veterinary Medicine, Universiti Putra Malaysia, Serdang, Selangor 43400 UPM, Malaysia. Institute of Agrobiotechnology, Serdang, Malaysia. ${ }^{4}$ Faculty of Medicine, Universiti Putra, Serdang, Malaysia.

Received: 31 December 2012 Accepted: 30 September 2013 Published: 21 October 2013

\section{References}

1. Ismail R, Allaudin ZN, Mohd Lila MA: Scaling-up recombinant plasmid DNA for clinical trial: Current concern, solution and status. Vaccine 2012, 30:5914-5920.

2. Palomares LA, Estrada-Modaca S, Ramírez OT: Production of recombinant proteins. Recomb Gene Expr 2004, 267:15-51.

3. Leader B, Baca QJ, Golan DE: Protein therapeutics: a summary and pharmacological classification. Nat Rev Drug Discov 2008, 7:21-39.

4. Noteborn MHM, Koch G: Chicken anemia virus infection: molecular basis of pathogenicity. Avian Pathol 1995, 24:11-31.

5. Leliveld SR, Dame RT, Mommaas MA, Koerten HK, Wyman C, Danen Van Oorschot AAAM, Rohn JL, Noteborn MHM, Abrahams JP: Apoptin protein multimers form distinct higher-order nucleoprotein complexes with DNA. Nucleic Acid Res 2003, 31:4805-4813.

6. Li J, Wang H, Ma Z, Fan W, Li Y, Han B, Zhang Z, Wang J: TAT-Apoptin induces apoptosis in the human bladder cancer EJ cell line and regulates $\mathrm{Bax}, \mathrm{BCl}-2$, caspase- 3 and survivin expression. Exp Ther Med 2012, 3(3):1033-1038.

7. Los M, Panigrahi S, Rashedi I, Mandal S, Stetefeld S, Essmann F, Schulze Osthoff K: Apoptin, a tumor-selective killer. Biochim Biophys Acta 2009, 1793:1335-1342.

8. Danen V, Oorschot AA, Zhang YH, Leliveld SR, Jennifer LR, Maud CMJS, Marian WB, Van Zon A, Stefan JE, Jan Pieter A, Dominik M, Mathieu HMN: Importance of Nuclear Localization of Apoptin for Tumor-specific Induction of Apoptosis. J Biol Chem 2003, 30:27729-27736.

9. Poon IKH, Oro C, Dias MM, Zhang J, Jans DA: Apoptin nuclear accumulation is modulated by a CRM1-recognized nuclear export signal that is active in normal but not in tumor cells. Cancer Res 2005, 65:7059-7064

10. Rohn JL, Zhang YH, Aalbers RIJM, Otto N, Den Hertog J, Henriquez NV, VandeVelde CJH, Kuppen JJK, Mumberg D, Donner P, Noterborn MHM: A tumor-specific kinase activity regulates the viral death protein apoptin. J Biol Chem 2002, 277:50820-50827.

11. Lee YH, Cheng CM, Chang YF, Wang TY, You CY: Apoptin T 108 phosphorylation is not requied for its tumor-specific nuclear localization but partially affects its apoptotic activity. Biochem Biophys Res Commun 2007, 354:391-395.

12. Zhou S, Zhang M, Zhang J, Shen H, Tangsakar E, Wang J: Mechanisms of Apoptin-induced cell death. Med Oncol 2012, 29:2985-2991.

13. Lanz HL, Suijker J, Noteborn MHM, Backendorf C: Proteasomal insensitivity of apoptin in tumor cells. Biochem Biophys Res Commun 2012, 422:169-173.

14. Yuan L, Zhang L, Dong X, Zhao H, Li S, Han D, Liu X: Apoptin selectively induces the apoptosis of tumor cellsby suppressing the transcription of HSP70. Tumor Biol 2013, 34:577-585.

15. Leliveld R, Zhang Y, Rohn J, Noteborn M, Abrahams P: Apoptin induces tumor-specific apoptosis as a globular multimer. J Biol Chem 2002, 278:9042-9051.

16. Zhang YH, Leliveld R, Kooistra K, Molenaar C, Rohn J, Tanke HJ, Abrahams $J$ J, Noteborn M: Recombinant Apoptinmulitmers kill tumor cells but are nontoxic and epitope-shielded in a normal cell specific fashion. Exp Cell Res 2003, 289:36-46.

17. Lim SN, Zeenathul NA, Mohd Azmi ML, Abas Mazni O, Fauziah O: Effect of protein concentration and injection pressure in microinjectiondelivery of maltose binding protein into breast cancer cells. Pertanika J Sc Tech 2012, 19:273-283.

18. Rose DW: Genetic manipulation of mammalian cells by microinjection. In Gene Transfer: Delivery and Expression of DNA and RNA, Volume 7. Edited by Friedmann R. Cold Spring Harbor, NY, USA: Cold Spring Harbor Laboratory Press; 2007.

19. Zhang Y, Yu LC: Microinjection as a tool of mechanical delivery. Curr Opin Biotechnol 2008, 19(5):506-510. 
20. Rohn JL, Noteborn MH: The viral death effector Apoptin reveals tumorspecific processes. Apoptosis 2004, 118:274-276.

21. Zhang YH, Kooistra K, Pietersen A, Rohn JL, Noteborn MHM: Activation of the Tumor-Specific Death Effector Apoptin and Its Kinase by an NTerminal Determinant of Simian Virus 40 Large T Antigen. J Virol 2004, 78:9965-9976.

22. Heilman DW, Teodoro JG, Green MR: Apoptinnucleocytoplasmic shuttling is required for cell type-specific localization, apoptosis, and recruitment of the anaphase-promoting complex/cyclosome to PML bodies. J Virol 2006, 80:7535-7545.

23. Yang JF, Wang JS, Zuo YG, Zhan H: Molecularly modified VP3 (30-121) induces apoptosis inhuman bladder cancer (EJ) cells but not in normal (3T3) cells. Cell Biol Int 2012, 36:1037-1042.

24. Tavassoli M, Guelen L, Luxon BA, Gäken J: Apoptin: specific killer of tumor cells. Apoptosis 2005, 10:717-724

25. Lee MS, Sun FC, Huang CH, Lien YY, Feng SH, Lai GH, Lee MS, Chao J, Chen $\mathrm{HJ}$, Tzen JTC, Cheng HY: Efficient production of an engineered Apoptin from chicken anemia virus in a recombinant E. coli for tumor therapeutic applications. BMC Biotechnol 2012, 12:27-41.

26. Yasuhiro S: Exploring Transduction Mechanisms of Protein TransductionDomains (PTDs) in Living Cells Utilizing Single-Quantum DotTracking (SQT) Technology. Sensors 2013, 12:549-572.

doi:10.1186/1471-2407-13-488

Cite this article as: Shen Ni et al: Selective apoptosis induction in MCF-7 cell line by truncated minimal functional region of Apoptin. BMC Cancer 2013 13:488

\section{Submit your next manuscript to BioMed Central and take full advantage of:}

- Convenient online submission

- Thorough peer review

- No space constraints or color figure charges

- Immediate publication on acceptance

- Inclusion in PubMed, CAS, Scopus and Google Scholar

- Research which is freely available for redistribution 